\title{
Opsoclonus myoclonus ataxia syndrome in severe acute respiratory syndrome coronavirus-2
}

\author{
João Fernandes $^{1}$ (D) Peter Puhlmann ${ }^{1}$ \\ Received: 19 October 2020 / Revised: 9 March 2021 / Accepted: 19 March 2021 / Published online: 31 March 2021 \\ (c) Journal of NeuroVirology, Inc. 2021
}

\begin{abstract}
A patient presented with an opsoclonus-myoclonus-ataxia syndrome after a 2-week period of fever. In her work as an assistant nurse, she had been exposed to patients infected with severe acute respiratory syndrome coronavirus-2. Laboratory investigations showed that the patient had positive IgG antibodies against this pathogen, and a chest CT showed changes compatible with this infection. Other known causes for this syndrome were excluded. Our case shows that the opsoclonusmyoclonus-ataxia syndrome can occur as a post-/para-infectious manifestation in patients infected with severe acute respiratory syndrome coronavirus- 2 .
\end{abstract}

Keywords SARS-CoV-2 $\cdot$ Post-infectious $\cdot$ Gait disorders/ataxia $\cdot$ Myoclonus $\cdot$ Opsoclonus

\section{Introduction}

Opsoclonus-myoclonus-ataxia (OMA) is a rare neurological syndrome that can have several underlying causes (Klaas et al. 2012). It is usually due to a paraneoplastic process, but it can also be para-infectious (Saini et al. 2020).

We are facing a current epidemic caused by the severe acute respiratory syndrome coronavirus-2 (SARS-CoV-2), where the number of infected patients worldwide has reached millions. The virus causes mainly respiratory symptoms, but it can be associated with the emergence of neurological symptoms or syndromes (Ellul et al. 2020).

We report the case of a patient with an OMA syndrome associated with an infection with SARS-CoV-2.

\section{Clinical report}

A 58-year-old woman had fever without any other symptoms for 2 weeks. Afterward, she felt well for 3 days but developed again fever, tremor, and difficulty walking, prompting admission to the hospital.

João Fernandes

joao.fernandes@vgregion.se

1 NÄL, Norra Älvsborgs Länssjukhus, Lärketorpsvägen 20, 46173 Trollhattan, Sweden
Physical examination revealed a tired patient with gait ataxia, dysarthria, and generalized tremor. Lung auscultation revealed crepitations over the right lower lobe. All vital parameters were normal. The $\mathrm{C}$-reactive protein was $48 \mathrm{mg} / \mathrm{L}$, and there was mild leukocytosis with normal hemoglobin and red blood cell count. Hepatic, renal, and thyroid functions were normal.

A lumbar puncture showed no pleocytosis. The patient received meropenem and acyclovir and was isolated because she had been in contact with patients with SARS-CoV-2 infection in her work as an assistant nurse.

On the following day, PCR analysis from a nasopharyngeal swab was negative for influenza A, B, RS virus, and SARS-CoV-2. A second lumbar puncture showed no pleocytosis. Blood, urine, and nasopharyngeal cultures were negative. A thoracic computer tomography (CT) showed peripheral consolidated opacities dorsally along the right superior and inferior pulmonary lobes with discrete ground glass opacities in the middle lobe. The lateral part of the left superior lobe had a sparse opacity. These findings raised suspicion of an infection with SARS-CoV-2. Meropenem and acyclovir were discontinued. Contact was taken with the neurology team.

A new neurological examination showed multifocal spontaneous and action induced myoclonus, ataxia of the upper and lower extremities, severe truncal ataxia (Video 1), and opsoclonus (Video 2). We diagnosed a possible parainfectious opsoclonus-myoclonus-ataxia (OMA) syndrome 
and initiated treatment with clonazepam and immunoglobulines. An EEG showed no signs of seizures or epileptiform activity. Myoclonus improved with clonazepam and levetiracetam. An MRI was normal. Despite treatment with immunoglobulins, the patient continued to display myoclonus, opsoclonus, and ataxia. She was therefore treated with corticosteroids. A paraneoplastic antibody panel analysis (CSV2, amphiphysin, Ma/2, Tr, Sox 1, Zic4, GAD, NMDA, LG11, CASPR2, GABA-B, VGCC PQ, AMPA 1/2, DPPX, $\mathrm{Hu}, \mathrm{Ri}, \mathrm{Yo}, \mathrm{PCA} 2$ ) was negative in both serum and the cerebrospinal fluid. Tumor markers (AFP, LD, S100B, bhcG, beta2-microglobuline, CA125, CA19-9, CA15-3, CEA, calcytonin) were negative. HIV, hepatitis B and C serologies were negative. A PET-CT scan showed no signs of malignancy. A serological analysis revealed the presence of $\operatorname{IgG}$ antibodies against SARS-CoV-2.

\section{Discussion}

Our patient presented the classical syndrome of OMA, and the clinical history together with the course of the disease led to the suspicion of a para-infectious etiology.

The patient developed fever during a period where the coronavirus epidemic was in full force in Sweden, and she had been in contact with patients infected with SARSCoV-2. Recent literature (Lomoro et al. 2020) describes peripheral lower lobe consolidation and ground glass opacities as the most common CT findings in patients with SARSCoV-2 infection, findings that were also consistent with our case. We moreover identified she had positive IgG antibodies to SARS-CoV-2. RNA from SARS-CoV-2 could not be shown from the upper airways with PCR because the test was made 2 weeks after the debut of fever.

Whenever an infectious etiology is involved in OMA, either direct invasion of the pathogen into the central nervous system occurs, or an immune-mediated pathological mechanism is set in motion, further driving a neuro-inflammatory response that affects the neural circuitry at the level of the pons and cerebellum (Saini et al. 2020). Known viral pathogens that have been involved in cases of OMA are HIV, West Nile virus, enteroviruses, influenza, varicella, human herpes virus 6, Epstein-Barr virus, and cytomegalovirus (Radu et al. 2018).

A recently published article (Rábano-Suárez et al. 2020) described the emergence of myoclonus in 3 patients with SARS-CoV-2 but without opsoclonus. Since the debut of the current coronavirus pandemic, other articles (Ellul et al. 2020; Orsini et al. 2020) have reported different neurological complications that can arise in the context of this disease, such as encephalitis, ischemic and hemorrhagic stroke, cerebral venous thrombosis, and Guillain-Barré syndrome.
There is uncertainty regarding the definition of parainfectious neurological syndromes as we do not have an infallible method that can differentiate whether a neurological syndrome depends on the direct invasion of a pathogen into the central nervous system or is a consequence of the immunological response. Criteria were proposed by some authors (Gotkine et al. 2010) in order to differentiate these two processes. One of them is that the neurological syndrome "appears following recovery from an infection/ vaccination, or if there is evidence of active neurological disease, following full resolution of infection" (Gotkine et al. 2010). In our case, the neurological symptoms started after a 2-week period of fever plus 3 days after the patient had been asymptomatic. A recent study (Guilmot et al. 2020) of 13 patients with SARS-Cov-2 and neurological symptoms showed an association between CSF pleocytosis and postinfectious encephalitis and polyradiculitis in two patients, where PCR analysis for SARS-Cov-2 in the CSF was negative in all patients. In the rest of the patients, the CSF had no pleocytosis. In our case, two lumbar punctures failed to show pleocytosis, which makes direct CNS invasion of an infectious pathogen unlikely.

Our diagnostic workup included an investigation of a possible underlying malignancy, as a paraneoplastic cause is frequently involved in adults who present with OMA syndrome (Armangué et al. 2016). A thorough investigation failed to show the presence of malignant lesions. No metabolic derangements were found.

It therefore remains as a putative disease mechanism a para-infectious etiology which in our patient was associated with a previous infection with SARS-CoV-2. We therefore propose adding SARS-CoV-2 to the list of known pathogens to be related with the OMA syndrome as a para-infectious manifestation.

Supplementary Information The online version contains supplementary material available at https://doi.org/10.1007/s13365-021-00974-0.

\section{References}

Armangué T, Sabater L, Torres-Vega E, Martínez-Hernández E, Ariño $\mathrm{H}$, Petit-Pedrol M, Planagumà J, Bataller L, Dalmau J, Graus F (2016) Clinical and immunological features of opsoclonus-myoclonus syndrome in the era of neuronal cell surface antibodies. JAMA Neurol 73(4):417-424. https://doi.org/10.1001/jamaneurol. 2015.4607

Ellul MA, Benjamin L, Singh B, Lant S, Michael BD, Easton A, Kneen R, Defres S, Sejvar J, Solomon T (2020) Neurological associations of COVID-19. Lancet Neurol 19(9):767-783. https://doi.org/ 10.1016/S1474-4422(20)30221-0

Gotkine M, Kennedy PG, Steiner I (2010) Post infectious CNS disorders: towards a unified approach. J Neurol 257(12):1963-1969. https://doi.org/10.1007/s00415-010-5743-9

Guilmot A, Slootjes SM, SellimiBronchainHanseeuw AMB, Belkhir L, Yombi JC, De Greef J, Pothen L, Yildiz H, Duprez T, Fillée C, 
Anantharajah A, Capes A, Hantson P, Jacquerye P, Raymackers JM, London F, ElSankari S, Ivanoiu A, Maggi P, van Pesch V (2020) Immune-mediated neurological syndromes in SARS-CoV-2-infected patients. J Neurol 30:1-7. https://doi.org/10.1007/s00415-020-10108-x

Klaas JP, Ahlskog JE, Pittock SJ, Matsumoto JY, Aksamit AJ, Bartleson JD, Kumar R, McEvoy KF, McKeon A (2012) Adult-onset opsoclonus-myoclonus syndrome. Arch Neurol 69(12):15981607. https://doi.org/10.1001/archneurol.2012.1173

Lomoro P, Verde F, Zerboni F, Simonetti I, Borghi C, Fachinetti C, Natalizi A, Martegani A (2020) COVID-19 pneumonia manifestations at the admission on chest ultrasound, radiographs, and CT: single-center study and comprehensive radiologic literature review. Eur J Radiol Open 7:100231. https://doi.org/10.1016/j. ejro.2020.100231

Orsini A, Corsi M, Santangelo A, Riva A, Peroni D, Foiadelli T, Savasta S, Striano P (2020) Challenges and management of neurological and psychiatric manifestations in SARS-CoV-2 (COVID19) patients. Neurol Sci 41:2353-2366. https://doi.org/10.1007/ s10072-020-04544-w
Rábano-Suárez P, Bermejo-Guerrero L, Méndez-Guerrero A, ParraSerrano J, Toledo-Alfocea D, Sánchez-Tejerina D, Santo-Fernández T, Folgueira-López MD, Gutiérrez-Gutiérrez J, Ayuso-Gacía B, González de la Aleja J, Benito-León J (2020) Generalized myoclonus in COVID 19. Neurology 11;95(6):e767-e772. https://doi. org/10.1212/WNL.0000000000009829

Radu RA, Terecoasa EO, Ene A, Bajenaru OA, Tiu C (2018) Opsoclonusmyoclonus syndrome associated with West-Nile Virus infection: case report and review of the literature. Front Neurol 9:864. https://doi.org/10.3389/fneur.2018.00864

Saini L, Dhawan SR, Madaan P, Suthar R, Saini AG, Sahu JK, Sankhyan N (2020) Infection-associated opsoclonus: a retrospective case record analysis and review of literature. J Child Neurol 35(7):480-484. https://doi.org/10.1177/0883073820911327

Publisher's Note Springer Nature remains neutral with regard to jurisdictional claims in published maps and institutional affiliations. 